\title{
The method of the best performer selection based on a competency-based approach
}

\author{
Anna Bakanova ${ }^{1, *}$, and Aleksey Nikolaevich Shikov ${ }^{2}$ \\ ${ }^{1}$ ITMO University, 197101, KronverkskyPr.49,Saint Petersburg,Russia \\ ${ }^{2}$ The Russian Presidential Academy of National Economy and Public Administration (North-West \\ Institute of Management, branch of RANEPA), 199178, Sredny prospect VO 57/43, Saint Petersburg, \\ Russia
}

\begin{abstract}
One of the important areas that determine the company's strategic development is human resource management. Information technology in this area is a crucial tool that implements many management functions, eliminating the human factor, facilitating the work of managers and improving performance indicators of work activities. The paper presents a method for finding the best performer based on a competencybased approach. Because of the ontologies use, it was possible to implement a complex multi-criteria search, which became the basis for organizing corporate training and monitoring competencies in the company.
\end{abstract}

\section{Introduction}

The development of information tools in the field of human resource management is an important and urgent issue in modern companies. Intellectual support of such processes as the assignment of an employee to a work task or project, training and career planning, human resource planning expands the company's ability to achieve strategic goals. Understanding the relationship of these processes and a wise approach to themanagement organization increases the productivity of employees and has a positive effect on the organization development as a whole. An increase in human resource management by $1 \%$ gives an increase in organizational innovation by $16 \%$. [1]

The main bond connecting such administrative and executive functions of human resource management as control, organization, adaptation, personnel recruitment, development and training, planning of personnel and work process is competence. This term is interpreted in differetly, but the greatest semantic value is its relationship with the work task performed by the employee. The main feature lies in the symmetric relationship: "the employee performs the work task because he possesses the necessary competence for this" and "the employee has the necessary competence, which means he is able to complete thework task." From the first expression, the idea arises that an employee can acquire a new competence through the performance of a work task, training takes place on the job.

\footnotetext{
*Corresponding author: bakanova55anna@gmail.com
} 
From the second expression, the idea arises that the employee first learns, gains competence, and then gets the opportunity to perform a work task. Both ideas, together with the task of finding the best performer, formed the basis of the method for finding the best performer which relies on a competency-based approach.

\section{Materials and methods}

\subsection{Existing solutions review}

Competency management process informatization in connection with various processes in the organization, including the workflow, is represented by many papers. In particular, in [2], an example of the graphs use in project management for resource allocation is given, but in this case it becomes impossible to compare all employees in terms of training. In works [3-6], the use of competencies is considered for recruiting a team and developing a career. However, these works do not consider the possibility of assigning an employee to specific tasks, and his development based on motivation to acquire competence for solving specific problems. The set of employee competencies is compared with the required set for the position or role, and only on this basis, the distribution of tasks occurs $[3,7,8]$. The issue of motivated learning and improving productivity is partly realized via gamification, when the acquisition of new knowledge and skills is supported by a goal that is understandable for the employee. For example, an increase through training in a level in a particular rating will have an impact and lead to positive changes in the working environment. While most often the purpose of human resources allocation is to minimize the time required to complete a work task or project [9-11].

Since the concept of competence is directly related to the training field, it was used to create systems dedicated to corporate training and the accumulation of knowledge [12-16]. This kind of systems makes it possible to identify gaps in knowledge and form a recommendation for employees training, however, the relationship between training and employee development in relation to the work process and competencies control in the company remains unrealized.

Most HR systems use an ontological approach [17-23]. Ontologies are the most functional tool for the classification and aggregation of any information. They help combine different directions of interaction with data and form a knowledge base for control systems. The ontologies use in the design of the method combines the problem of creating a competency base in a company that is used to find a suitable performer and organize corporate training.

The proposed method allows one to define the requiredlearning goals, eliminate manipulability when assigning an employee, reduce discussion time when assigning tasks, and is suitable for both a project approach and a product (Scrum) approach.

\subsection{Method ideas in personnel management, problem statement}

The main idea of the method is to support corporate training as a result of constant competencies monitoring in the process of selecting the best performer for a work task. There are three urgent management problems of the company's competencies, which are solved using the method:

- Creation of a critical situation in the absence of a key specialist,

- Formation of the company's competence base,

- Support for effective corporate training 
When searching for a suitable contractor for solving a work task, various ratings are formed that clearly represent the situation in the company with respect to specific competencies and situations with the solution of specific work tasks. The method algorithm lies in finding the best performer and analyzing the information obtained by comparing the values of the criterion compatibility for the employee with the reference value for the criterion.

The search organized within the framework of the method is aimed at solving a task/problem $(E)$ which relies on a competence-based approach. To solve various types of tasks / problems, two types of search are set: single-purpose $\left(E_{l}\right)$ and multi-purpose $\left(E_{2}\right)$. In a single-purpose search, the best performer is selected, taking into account the competencies that he or she possesses, the conditions that must be met for the implementation of activities and restrictions on the number of simultaneously performed tasks. In multipurpose search, in addition to selecting the best performer, the situation is analyzed with the possibility of performing a specific task by other employees and competencies monitoring in the company. Because of the formation of ratings, employees are distributed according to the levels of training regarding the solution of a specific task.plann

The method solves the following tasks / problems:

- Search for a specific employee for a position $\left(E_{l}\right)$,

- Search for a specific employee to complete a work task $\left(E_{1}\right)$,

- Search for a specific employee to be assigned to a project $\left(E_{l}\right)$,

- Finding a group of employees to complete a work task $\left(E_{2}\right)$,

- Search for a group of employees for assignment to the project $\left(E_{2}\right)$,

- Team / department competency analysis $\left(E_{2}\right)$,

- Company competency monitoring $\left(E_{2}\right)$.

Employee training is recommended based on search results and is aimed primarily at controlling competencies in the company and supporting work activities. But,simultaneously, thanks to the visual representation of one's training in relation to work activity through the formed ratings, the mechanics of influence and status,reward, development andcompetition are implemented. These game mechanics create learning motivation and personal development preferences in employees. The information management structure of a corporate training organization is shown in Figure 1.

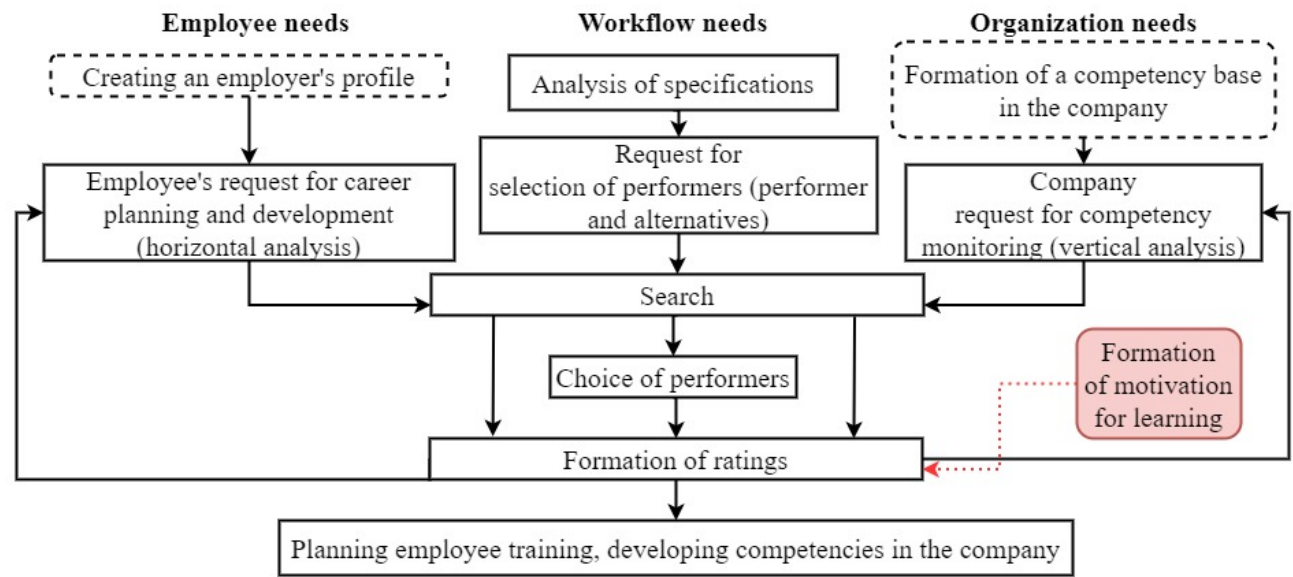

Fig. 1. The information management structure of corporate learning

The correct goals setting is important not only for the educational process, but also for work activities. When combining the required learning objectives, both the organization's 
requirements for the training of the employee and his personal and professional motives are taken into account.

\subsection{Method development for choosing the best performer}

The developed search model is based on a partially automated method for analyzing hierarchies, which, in line with the linear convolution method, allows solving the problem of multi-criteria choice and building a consistent hierarchy of estimates for all participants in the workflow.

For this, the reference value of compatibility is calculated for the selected set of competencies and conditions (criteria) corresponding to the task / problem. Then the reference value is compared with the compatibility result for each employee [24]. Compared are those employees who are pre-selected according to external conditions: from the same team, department, etc.

The set of criteria is represented by formula (1), where $K(E)$ is a set of competencies necessary to solve a search problem, $U(E)$ is a set of conditions necessary to solve a search problem, respectively, formulas (2) and (3):

$$
\begin{aligned}
& C(E)=\left\{c_{1}, c_{2}, \ldots, c_{m}\right\}=K(E) \cup U(E) \\
& K(E)=\left\{K_{l}(E), K_{2}(E), \ldots, K_{l}(E)\right\} \\
& U(E)=\left\{U_{l}(E), U_{2}(E), \ldots, U_{z}(E)\right\}
\end{aligned}
$$

Criteria are assigned with importance and weight values. The weight is assigned by means of a peer review method. When searching for the best performer for a work task or project, a set of criteria and their weights are generated automatically by analyzing the specifications. For other tasks, the formation of search criteria sets and their importance is carried out by an expert: an employee of the HR department, head of a department, etc.

The search model looks like the following formula (4):

$$
\begin{aligned}
& y=\left(P_{\text {exp }}, D, y_{1}, y_{2}, y_{3}, Z\right) \\
& y_{1}=\left(P_{H i g h}, P_{D e v}, P_{\text {Low }}\right) \\
& y_{2}=\left(S I_{H i g h}, S I_{D e v}, S I_{\text {Low }}\right) \\
& y_{3}=\left(S K_{H i g h}, S K_{D e v}, S K_{\text {Low }}\right)
\end{aligned}
$$

where $y_{1}-$ the plurality of sets reflecting the ratings of employees on request is represented by the formula (5)

$y_{2}-$ plurality of sets reflecting horizontal analysis, formula (6).

$y_{3}-$ plurality of sets reflecting vertical analysis, formula (7).

The $P_{\text {exp }}$ expert for a task / problem is the employee with the maximum compatibility score, which is calculated for each of the considered employees. Such an expert is the key employee for a specific work task or project. The choice of the best performer $D$ occurs when solving tasks $E_{l}$, taking into account the maximum number of tasks simultaneously performed by an employee. Accordingly, this employee may be busy or absent, and there is a need to determine alternative replacement options. The plurality of sets $y_{l}$ represents alternative options for choosing a suitable executor $\left(P_{H i g h}\right)$ a set of potentially trained employees $\left(P_{D e v}\right)$ and those for whom compatibility by criteria is minimal for performing a work task $\left(P_{\text {Low }}\right)$. The plurality of sets $y_{2}$ is responsible for horizontal analysis, which makes it possible to distribute the employee's competencies by compatibility levels. The plurality 
of sets $y_{3}$ is responsible for vertical analysis, which makes it possible to divide employees according to the level of proficiency in the criterion and identify the lack of competencies in the company. Searchrestrictionsarerepresentedbytheset $Z$.

The analyzed information on competencies, in addition to being used when choosing the best performer, is reflected in the employee's profile. Thus, everyone can see their weak competencies and performance level of work tasks. The results of the vertical and horizontal analyzes are used to create customized learning paths.

\subsection{Method realization}

In order to implement the method, a module of a corporate e-learning system was developed for accounting and working with employee competencies based on an ontological approach. The module interacts with third-party services and ontologies. Interaction with third-party services is carried out through the analytical subsystem, which is responsible for the semantic analysis of specifications and the assignment of sets of competencies and conditions to work tasks and projects. The latest specifications are provided by third-party services, which describe the necessary requirements for completing work tasks / projects. Thanks to this approach, there is a constant cycle of interaction between the workflow and employee training.

Competencies and conditions are assigned to a work task (specification analysis), according to the assigned set of criteria, the search for the best performer for the work task is carried out, the employee receives a new competency (training / work performance). This cycle is carried out through the use of ontologies.

Due to the data reusability, the use of ontologies is most effective for building intelligent search engines and creating corporate information services. Convenient storage, updating, classification and aggregation of knowledge have improved the field of e-learning knowledge management in the organization. The ontological model of competencies used to implement the method is organized in such a way as to create a hierarchical structure of competencies in the company. The competences of the previous level together with the conditions form new competencies [22, 24]. Using a condition as a component of a competency expands the functional use of competencies. There is an opportunity to create intra-organizational competencies used to organize the work process and search for performers, taking into account the specifics of the company's activities. Such a structure is also more understandable for the employees themselves, since the relationship between different competencies is structured through their component parts. At the same time, the classical representation of competence (KLM) is preserved as a set of knowledge, skills and abilities [17, 23].

Figure 2 shows an algorithm for assigning a competency to an employee after completing a work task. 


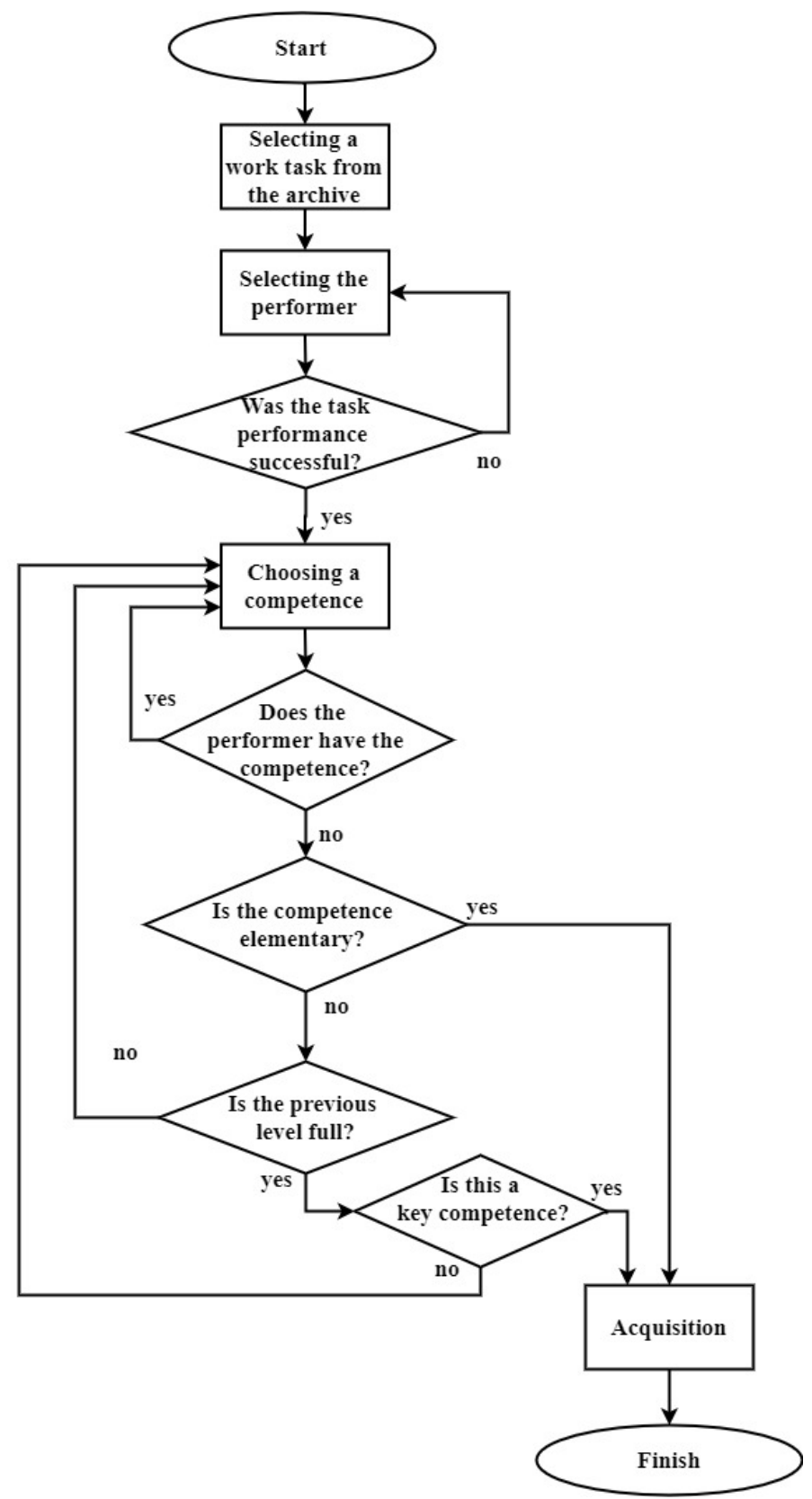

Fig. 2. Algorithm for assigning competencies to an employee based on the results of a work task

\section{Results and discussion}

The method of finding the best performer based on the competence-based approach was developed for SCOUT Group of Companies and showed good efficiency results. To compare automatic and expert solutions, a number of special evaluation criteria have been developed. The experiment was carried out in several stages and included the assignment of competencies and conditions to work tasks, the distribution of their weight and the selection 
of performers. The accuracy of selection and a positive assessment by experts of the automatic competencies selection was $85.6 \%$ and $91.6 \%$, respectively. Given the hierarchical structure of competencies, a high rate of selection accuracy affects the correct selection of a performer. Since the correctness of the expert choice for a work task is from 80 to $90 \%$, it indicates that at least 8 out of 10 competencies are involved in the appointment of the required performer. And these 8 competencies are the main ones for the assignment. The weight value for matching competencies falls within the confidence interval of $95 \%$. The performer's automatic selection and the distribution of training levels were rated positive by $88 \%$ of employees. More than half of the 15 survey participants surveyed found the rating-based training recommendations helpful.

The method's practical significance is reflected in the increase in productivity from $13 \%$ to $27 \%$, the number of successfully completed tasks in the customer support department has doubled. The employees got the opportunity to implement internal organizational tasks aimed at improving the company's performance.

It should be noted that an important condition for applying the method is the company's willingness to develop competencies and an accurate attitude to the knowledge base. In order for the method to work correctly, it is necessary to conduct an accurate initial assessment of the employee's competencies using proven information collection methods. It is worth excluding the possibility of an employee's self-preparation of a competency map, and using high-quality expert assessment methods. Since providing false information makes work activities, personal training and employee development ineffective.

The next factor influencing the positive use of the method is the structure and composition of the specification for work tasks and projects. It should contain the following main sections, avoiding duplication of information and preserving the maximum amount of information:

- Introduction.

-General characteristics.

- Description of requirements.

- Direct description of the work task / project.

-Additional requirements.

\section{Conclusions}

The development of information systems in the field of company's human resource management faces many challenges. Duplication of functions in various structures of the organization leads to redundancy of information, difficulty in combining numerous factors and analysis of aexcessive amount of information. The presented method showed that when combining competency monitoring with workflow and training, it is possible to increase productivity efficiency and affect motivation to learn. It made it possible to implement various management functions and support the adoption of managerial decisions. The use of competence as a key element enabled combination of the search for the best performer for a work task with the organization of corporate training. This approach to the control of competencies in the company contributed to development of new recommendations for training and career planning. Through the compilation of ratings, deficient competencies in the company are identified and personal training paths for employees are formed.

\section{References}

1. S.A.Hashemi, F. Dehghanian, Eng. Technol. Appl. Sci. Res.,7, 2200 (2017) 
2. B. H. Burkov, A. Ju. Zalozhnev, D. A. Novikov, Teorijagrafov v upravleniiorganizacionnymisistemami, 124 (2001)

3. C. Kimble, J.B. de Vasconcelos, Á. Rocha, Inf. Syst.Front.,18, 1119 (2016)

4. C.Dorn, F. Skopik, D. Schall, S. Dustdar,Data Knowl. Eng.,70, 866 (2011)

5. J.Decius, N.Schaper, Procedia Manuf.,9, 376 (2017)

6. F. L. Krause, W. Hacker, U. Debitz, C. Kind, M. Strebel, CIRP Ann, Manuf. Technol., 55, 135 (2006)

7. L. Fernández-Sanz, J. Gómez-Pérez, A.Castillo-Martínez, Comput. Stand. Interfaces.,51,30 (2017)

8. S. N.Neborskij, Rep. Bel. Univ. of Inf. and Radioelectronics, 2, 73 (2009)

9. L.C.e Silva, A.P.C.S.Costa, Int. J. Proj. Manag.,31, 100 (2013)

10. R.V. Dopira, R.Ju. Kordjukov, A.A. Beglecov, S. V. Sergienko, Programmnyeproduktyisistemy,33, 22 (2014)

11. A.V.Kataev, T.M.Kataeva, E. L.Makarova, Izv. Sarat. Un.. New series. The Ec. Ser.. Manag.. Right, 16, 294 (2016)

12. J. M. Silva, J. H. Rosa, J. Barbosa et al., Brazilian Comput. Soc.,16, 163 (2010)

13. T. Ley et al., J. Knowl. Manag.,12, 31 (2008)

14. S. Oliveira, J. Carlos Gluz, Adv. in Exp. Med. and Biol.,41 (2010)

15. A.Garro, L.Palopoli,L. N. in Comp. Sc. (incl. subs. L. N. in Art. Intell. and Bioinf.),283(2003)

16. J.L. De Coi et al.,Webist 2007 - 3rd Int. Conf. on Web Inf. Sys. and Techn, Proc.,9 (2007)

17. W. Zaouga, L. B. A. Rabai, W. R. Alalyani, Procedia Comput. Sci.,151, 417 (2019)

18. H. Ma, H. Sven, V. Panrawee, Enterp. Model. Inf. Syst. Archit.,13, 182 (2018)

19. M.Mochol, R.Oldakowski, R.Heese, Proc. of the GI2004 Conference (2004)

20. S.Strohmeier, F.Röhrs, AIS Trans.on H-Comp. Inter.(2017)

21. J.L.V. Barbosa et al., Comput. Ind.,72, 27 (2015)

22. S. Miranda et al., Data Knowl. Eng.,107, 51 (2017)

23. J.H. Rosa et al., Int. J. Artif. Intell. Educ.,25, 455 (2015)

24. A.Bakanova, A.N.Shikov, CEUR Workshop Proceedings.,2590, 1 (2020) 